\title{
Exposing and selling the use of web services - an option to be considered in make-or-buy decision-making
}

\section{Authors:}

Steffen Zimmermann, Department of Information Systems, Production and Logistics Management, University of Innsbruck, Universitätsstrasse 15, A-6020 Innsbruck, Austria, Steffen.Zimmermann@uibk.ac.at

Marcel Müller, Department of Information Systems, Production and Logistics Management, University of Innsbruck, Universitätsstrasse 15, A-6020 Innsbruck, Austria, marcel.mueller@uibk.ac.at

Heinrich, Bernd, Department of Management Information Systems, University of Regensburg, Universitätsstrasse 31, D-93040 Regensburg, Germany, bernd.heinrich@ur.de

Citation: Steffen Zimmermann, Marcel Müller, Bernd Heinrich, Exposing and Selling the Use of Web Services - An Option to be considered in Make-or-Buy Decision-Making, Decision Support Systems, Volume 89, September 2016, Pages 28-40, ISSN 0167-9236, http://dx.doi.org/10.1016/j.dss.2016.06.006. (http://www.sciencedirect.com/science/article/pii/S0167923616300896) 


\section{Exposing and selling the use of web services - an option to be considered in make-or-buy decision-making}

Abstract: The emergence of the web service market has enabled firms to choose between developing web services internally and purchasing them externally from web service providers. In general, these socalled make-or-buy decisions have been the object of intense debate in the IT outsourcing literature. However, characteristics of web services such as loose coupling and the current trend of digitalizing application interfaces enable new opportunities especially to non-software firms: when a firm decides to develop a web service internally (make-decision) it has the option of exposing and selling the use of this web service after its internal development (sell option). In this paper, we propose a normative approach for the valuation of such a sell option based on real option theory, taking into account the characteristics of web services. This approach enhances traditional make-or-buy approaches by additionally considering this sell option in decision-making. Our results are twofold: (I) the sell option has considerable impact on traditional make-or-buy decisions and makes the internal development of web services more attractive; (II) it is preferable to execute the sell option as soon as possible after completion of the internal development of the web service.

Keywords: Make-or-buy decisions, Web services, Real option theory, Sell option, Web service market

\section{Introduction}

Service-oriented architectures have become the dominant design principle for application systems and enterprise architectures (e.g., [2, 22, 41, 81, 89]). This is due to the fact that web services (cf., [84] for their characteristics) promise to enable a flexible and cost-efficient execution of business processes because of their structure, communication, and interfaces that follow well-defined, general standards [82]. This trend is accompanied by an ever-increasing number of web services available on the web service market (e.g., platforms like programmableweb.com and appexchange.salesforce.com currently list over 15,000 web services). While some of these web services fulfill simple tasks like geo location, simple storage or shipment tracking, those offering complex functionalities like customer profiling, online payment services, credit scoring, and data cleansing have also been on the increase. Additionally, there are web services providing complex functionalities which are used only within a business-to-business domain and hence 
are not available on public internet platforms. Moreover, many of today`s web services are denoted as cloud services, despite using web service standards (e.g., protocols like SOAP or REST) to provide their functionality. Considering the increasing importance of service-oriented architectures and the rise of the web service market, it is evident that the more service-oriented architectures are implemented within firms (e.g., $[2,33,81]$ ) the more the question arises whether a firm should develop web services internally or buy them from an external web service provider.

Enabled by the abovementioned general standards of web services, non-software firms that decide to develop web services internally (make-decision) have the additional option of exposing and selling the use of these web services through digital application programming interfaces (Digital APIs) on the web service market [1]. We name this additional option as sell option which represents a "long call option" according to option theory (cf., [36], p. 197). The new phenomena of exposing and selling web services is part of several digital transformation initiatives of non-software firms [65] and exposing applications including web services through Digital APIs evolved to be the core business of many IT service providers such as akana.com, apigee.com, and mulesoft.com that support non-software firms in their digital transformation initiatives. Several non-software firms already expose their web services through Digital APIs. For example, Amazon sells its goods through third parties via its Product Advertising API, which in turn is made available for other uses through the Amazon Web Services API [59]. In addition, Mastercard exposes own web services to enable retailers to do a fraud scoring for e-commerce payment transactions and to check the validity of given addresses in the United States and Puerto Rico [53]. UPS also offers a similar so-called Address Validation Street Level API to external parties [83]. In the banking industry, the socalled Banking Industry Architecture Network (BIAN) aims to enable, among others, banks to expose their web services by “developing their semantic service definitions on a consistent basis (...) to enable internal and commercial service-oriented solutions according to a standardized industry model” [12]. In an interview we made with the chief architect of BIAN, he stated that members of the network already use the BIAN service designs to define and specify their services and APIs for internal and external use. For instance, the Development Bank of Singapore recently went live with a web-service-based product for consumers that uses the BIAN service designs. However, he also stated that many BIAN members are at 
the beginning of their digital transformation initiatives, meaning that the potential of exposing and selling the use of web services is not nearly exploited.

This sell option is especially relevant for web services that support non-strategic business processes. This is supported by literature on IT outsourcing (cf. Lacity et al. [46] for a review on motives for IT outsourcing) that generally indicates that highly individualized and sophisticated web services that are core capabilities to execute core business processes are usually not subject to make-or-buy decision-making due to strategic reasons. However, non-strategic, standardized and precisely defined business processes [20] are typically more suitable for outsourcing to enable firms to "focus on their core business" [46]. Thus, the sell option is especially relevant for web services that support these kind of business processes and could make it economically worthwhile to keep non-strategic and standardized business processes in-house (e.g., the online sales process of consumer loan contracts at a FSP described in Subsection 3.2), which may have been outsourced without considering the sell option.

Considering the new option of exposing and selling the use of web services in make-or-buy decisionmaking, we have to enhance traditional make-or-buy approaches by this sell option especially with respect to web services that support non-strategic and standardized business processes. Consequently, we state the following research question:

How to consider and evaluate the option of exposing and selling the use of a web service (sell option) in make-or-buy decision-making?

To answer this research question, we propose a normative approach based on real option theory that enhances traditional make-or-buy approaches by the sell option and apply this approach to a real-world example. Our results are twofold: (I) the sell option has considerable impact on traditional make-or-buy decisions and makes the internal development of web services more attractive; (II) it is preferable to execute the sell option as soon as possible after completion of the internal development of the web service. Especially result (II) contradicts the well-known result from real option theory that the option value increases in the option runtime (cf., [36], p. 387), but supports the intuition that a later launch of a web service on the web service market decreases value. 
We structure the remainder of this paper as follows. In the next section, we first discuss related literature and illustrate the research gap. Next, we describe the problem context and deduce modeling issues. Afterwards, we present our approach to value the sell option. Subsequently, we apply this approach in a real-world example. In the penultimate section, we validate the proposed approach, point out limitations and directions for future research. Finally, we conclude with a summary of our findings.

\section{Related literature}

In this section, we first discuss the most relevant articles about make-or-buy decision-making regarding IT services and especially web services. As real option theory represents the theoretical background to value the sell option and to enhance the valuation of the make alternative in existing make-or-buy approaches, we then briefly summarize articles that use real option analysis to value IT investments.

\subsection{Make-or-buy decision-making}

In the IS literature make-or-buy decision-making is extensively discussed in the context of IT outsourcing (see $[24,46]$ for reviews of IT outsourcing literature). Apart from a variety of empirical works (see [47] for an overview) a series of normative approaches to support make-or-buy decisions have been published in the last two decades (e.g., [85, 87]). In the following discussion of make-or-buy literature, we focus on normative make-or-buy approaches for IT services (e.g., components, modules) or especially web services, as the sell option we consider in this paper is only relevant for IT/web services that are tradable on a market. For instance, Cortellessa et al. [21] investigate whether a firm should buy commercial offthe-shelf components or develop them in-house. They incorporate costs as well as quality attributes in a non-linear cost-quality optimization model and also consider the architecture of the intended software system. Jha et al. [37] propose a fuzzy bi-criteria optimization approach for the selection of commercial off-the-shelf components to maximize intra-modular coupling density and functionality considering makeor-buy alternatives. Zhao et al. [88] suggest an analytical model for make-or-buy decisions on software components, which focuses on solving a cost-minimization problem that also considers other factors such as time to market and system reliability. Tansey and Stroulia [78] propose an approach for an economic evaluation of a business process which can be composed of multiple web services. Even though, they do not explicitly propose a make-or-buy approach, but by considering both choices in their evaluation procedure, they implicitly evaluate a make-or-buy decision. Braunwarth and Heinrich [18] specifically 
emphasize how to balance costs and risks of web services in their proposed portfolio optimization model. This model allows the decision maker to value a set of internally developed or externally obtained (web) services and aims to analyze risks associated with these services by integrating the risks into the optimization model. Dorsch and Häckel [25] investigate the capacity-planning problem of a service provider for a certain business process wherein the service provider can choose between outsourcing and executing different process steps by itself. Therefore, they develop an optimization model based on queuing theory to minimize total operating costs where the service provider can choose between the two different models of capacity supply (i.e., dedicated and elastic capacity) and additionally the opportunity to use surplus capacity from an external service market. Matros et al. [54] investigate make-or-buy decision-making regarding cloud services. They provide a cost-comparison approach and a break-even analysis to determine whether the make or the buy choice is economically worthwhile for a specific service. Moreover, some scholars briefly mention that the internal development of web services enables the option of exposing and selling the use of web services to other business partners (e.g., [31, 61, 62]). However, they do not propose an approach on how to value this option to enhance existing make-or-buy approaches. To the best of our knowledge, no existing make-or-buy approach considers the sell option. We contribute to this literature stream by proposing such an approach and examining the consequences of the sell option on make-or-buy decision-making.

\subsection{Real option analysis to value IT investments}

The option to expose and sell the use of a web service after its internal development constitutes a managerial flexibility that has to be taken into account when evaluating make-or-buy decisions. The consideration of managerial flexibilities in IT investment decision-making in general (see e.g., [26, 42, 44, 79]) and in the context of service-oriented architectures in particular (see e.g., [5, 32, 40]) are extensively discussed in IS literature by using real option analysis approaches. These approaches typically use financial option pricing models with the predominant model being the Black-Scholes Model to value different types of real options. Examples are the valuation of a deferral option to provide a point-of-sale debit card network to other companies [7], nested options that have different underlying IT investments [9], a set of strategic options from a shared services transformation [76], or a growth option on an IT investment where a company decides whether to migrate to the client/server version of SAP R/3 [79, 80]. Another applied 
model is the Margrabe Model [52], which is used to value, for example, an option portfolio of 31 e-business investments of a U.S.-based energy utility firm [6] or a growth option to justify investments in new technologies [26]. Further financial option pricing models that are used within the IS literature are the Binomial Model (e.g., [3]), or slightly adapted versions of the Black-Scholes Model (e.g., [8, 10]). The problem with the application of financial option pricing models on the evaluation of IT investments are their very restrictive underlying assumptions that are rarely validated as to whether they adequately represent the characteristics of IT investments in general or web services in our application context (cf. Section 3.3 for a detailed discussion). To the best of our knowledge there is no existing real option analysis approach that adequately represents the characteristics of web services in its underlying assumptions. We contribute to this literature stream by adapting the assumptions of the Black-Scholes Model in a way that they better represent the characteristics of web services and propose a real option analysis approach based on these adapted assumptions.

In this paper, we contribute to the make-or-buy literature on IT services and especially web services by proposing a normative approach on how to enhance traditional make-or-buy approaches by the so far unconsidered option to expose and sell the use of a web service on the web service market. We further contribute to the real option analysis literature on IT investments by not just using standard financial option pricing models such as the Black-Scholes Model to value the sell option (e.g. [34]), but determine modeling issues that are addressed in our approach to adequately represent the characteristics of web services (cf., $[11,55])$

\section{Decision problem}

To examine the make-or-buy decision problem in the context of web services, we first briefly analyze roles and business models on the web service market. Subsequently, we illustrate the decision problem by introducing a real-world example and deduce relevant modeling issues.

\subsection{Web service market}

According to Legner [49], Nüttgens and Dirik [62], Shang et al. [72], and Tang and Cheng [77] the market participants on the web service market can be differentiated between web service producer (WSP), web service consumer (WSC), and web service intermediary (WSI). WSPs can be (a) software firms that 
are specialized in providing web services against payment (e.g., Fraudlabs, Xignite, StrikeIron, or ServiceObjects) and (b) non-software firms that first and foremost develop web services for their internal use but may expose some of their internally developed, non-strategic web services (e.g. through digital APIs) and sell their use on the web service market. We take the perspective of (b) as mainly non-software firms are confronted with the make-or-buy decision problem.

On the web service market, a non-software firm has two opportunities to expose and sell its internally developed web service: a non-software firm can either act as WSP that hosts and sells the use of a web service on its own (Business Model 1) or act as WSP that mandates a WSI such as the platform appexchange.salesforce.com to host and sell the use of a web service on behalf of the non-software firm (Business Model 2). In the latter case, the non-software firm acting as WSP pays a commission fee to the WSI for hosting and selling the use of the web service. The WSI provides access to the web services for the WSC and transfers the payments from the WSC to the WSP. The two stylized business models on the web service market (note that there are hybrid forms as well) are illustrated in Fig. 1:

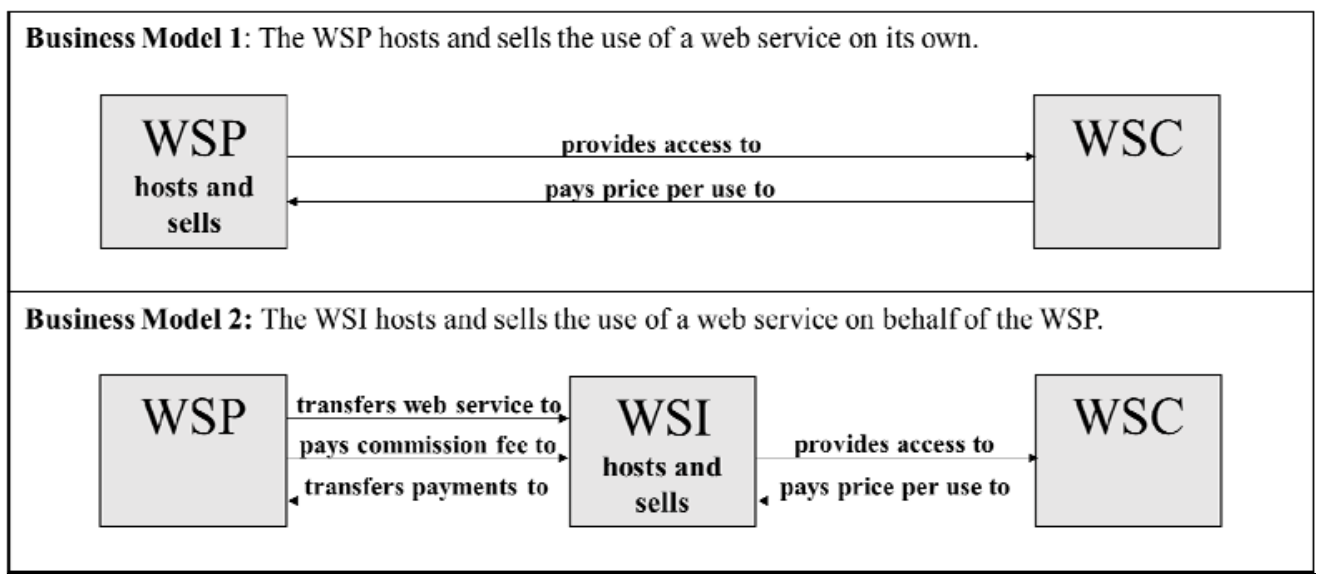

Fig. 1. Business Models on the Web Service Market

Since costs for exposing the web service can differ for the WSP between these two business models, we list the cost categories mentioned in literature and their relevance for the business models in Table 1 .

Table 1. Cost categories of the WSP for exposing a web service.

\begin{tabular}{|l|l|l|l|}
\hline Cost category & Description & $\begin{array}{l}\text { Relevant in } \\
\text { Business } \\
\text { Model 1 }\end{array}$ & $\begin{array}{l}\text { Relevant in } \\
\text { Business } \\
\text { Model 2 }\end{array}$ \\
\hline $\begin{array}{l}\text { Additional } \\
\text { development } \\
\text { costs }\end{array}$ & $\begin{array}{l}\text { Development costs that are required to expose a web service } \\
\text { such as costs for implementing digital APIs, for } \\
\text { implementing different web service versions, for constant } \\
\text { availability, etc. }\end{array}$ & Yes & Yes \\
\hline
\end{tabular}




\begin{tabular}{|l|l|l|l|}
\hline Hosting costs & $\begin{array}{l}\text { Hosting costs occur for providing the necessary } \\
\text { infrastructure including costs for security measures to secure } \\
\text { the hosting infrastructure. Moreover, these hosting costs } \\
\text { include costs for providing a website containing information } \\
\text { on the web service such as its functionality, configuration } \\
\text { possibilities, integration manuals, pricing, and demos. }\end{array}$ & Yes & No \\
\hline Marketing costs & $\begin{array}{l}\text { Marketing costs are required for advertising the placement of } \\
\text { a web service on the web service market. }\end{array}$ & Yes & No \\
\hline Billing costs & $\begin{array}{l}\text { Billing costs include effort for charging a WSC (e.g., } \\
\text { invoicing, checking receipt of payments). }\end{array}$ & Yes \\
\hline $\begin{array}{l}\text { Commissioning } \\
\text { costs }\end{array}$ & $\begin{array}{l}\text { Commission costs arise for the WSP when a WSI hosts and } \\
\text { sells the web service on behalf of the WSP and charges a } \\
\text { commission fee for its intermediation. }\end{array}$ & No & Yes \\
\hline $\begin{array}{l}\text { Costs for } \\
\text { embedded } \\
\text { services }\end{array}$ & $\begin{array}{l}\text { Costs for embedded services occur for web services that are } \\
\text { composed of other chargeable resources such as chargeable } \\
\text { external web services. }\end{array}$ & Yes & \\
\hline
\end{tabular}

\subsection{Real-world example}

To illustrate a WSP's make-or-buy decision problem, we use a real-world example representing Business Model 1 of a German multi-channel retail bank (MCRB) ${ }^{1}$. The MCRB's aim is to reach a higher degree of automation for its consumer loan processes and to establish a risk-adjusted pricing of consumer loans. It further plans to launch new consumer loan products (e.g., instant loans with low volumes). This prompts the need, therefore, to redesign the existing consumer loan processes, which in turn requires a review of, and potential changes to the existing IT landscape. MCRB's IT landscape (cf., Fig. 2) supports several distribution channels (especially the channels branch and internet) by means of a middleware, which provides composite services called business services that are composed of multiple web services (e.g., a business service for creating customers in the SAP BP system). The business services are used from different distribution channels, each having its individual web frontend. Apart from integrating MCRB's internal backend systems, the middleware connects frontends with external systems (e.g., of rating agencies such as Schufa).

\footnotetext{
${ }^{1}$ For reasons of confidentiality, all information that identify the bank are undisclosed.
} 


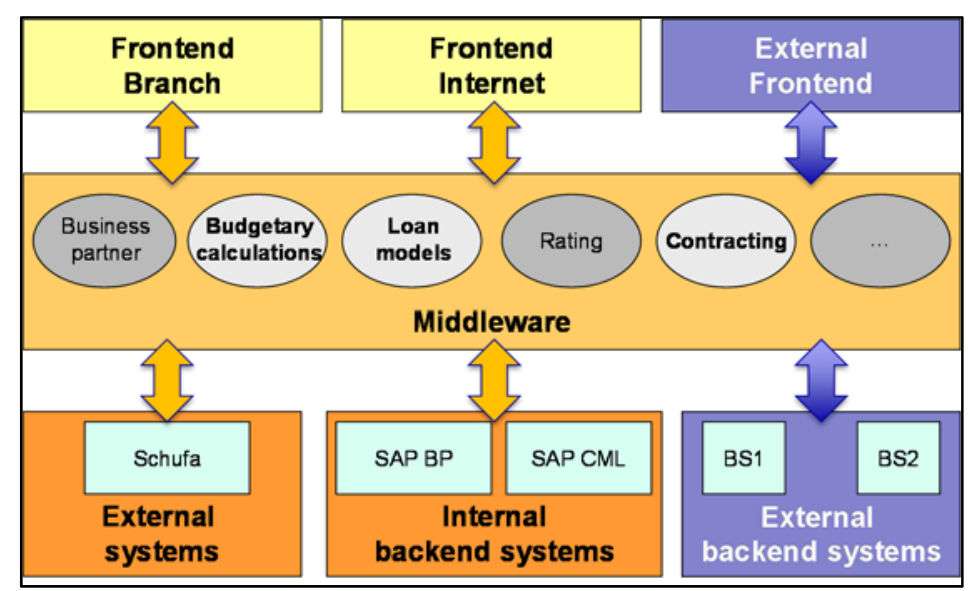

Fig. 2. IT landscape of the MCRB (simplified illustration).

Given the large potential for reusing web services embedded in other business processes (e.g., debit card processes) the redesign of the consumer loan processes have to retain its overall IT architecture. Moreover, the middleware already provides business services such as those for internally and externally rating customers. However, the redesign of consumer loan processes also have to involve some modifications and extensions. Apart from minor reviews of the existing web services, the following business services have to be developed (see white ovals in Fig. 2):

- Loan models: This business service provides different loan products, loan volumes, and loan runtimes, which can be chosen by customers, and returns a record that describes the calculated alternative loan models.

- Budgetary calculations: This business service generates an internal rating of potential customers and calculates the customer's available budget based on his/her stated monthly income and outgoings.

- Contracting: This business service determines whether the requested loan can be accepted, creates the documents for accepted loan contracts, and stores them in the SAP Consumer and Mortgage Loans (CML) system.

The MCRB can either develop the mentioned business services internally (make-decision) or buy a configurable web service-based standard solution (cf., [70]). Based on traditional make-or-buy approaches, the MCRB would make its decision based upon a cost comparison between the internal development costs for developing the business services and the costs for purchasing the external solution from the web service market. However, when evaluating the make decision, the MCRB contemplates to expose and sell the use 
of their business services to other FSPs by providing digital APIs that enable the communication with external frontends and backend systems (BS) of other FSPs (see right hand side of Fig. 2).

\subsection{Modeling issues}

As discussed in Section 2.2, the most frequently used approaches to value real options on IT investments are financial option pricing models such as the Black-Scholes Model (e.g., [9, 34, 80, 81]), the Binomial Model (e.g., [5]), or the Margrabe Model (e.g., [6, 26, 80]). As these models were initially designed for the valuation of financial options (cf., [13, 52]), their underlying assumptions are very restrictive and do not adequately represent the characteristics of IT investments. Consequently, financial option pricing models such as the Black-Scholes Model to value real options on IT investments have been criticized (e.g., [39, $43,60,71])$ on account of, mainly, the following four reasons:

1. Option Runtime: Financial option pricing models typically assume a certain and known option runtime and that the option can be executed either only at the end of the option runtime (i.e., European Option) or at an arbitrary point in time during the option runtime (i.e., American Option) (cf., [36], p. 194). The option to sell the use of an internal web service cannot be executed before the web service is developed. This means that the sell option has to be modeled as European Option. However, it can not only be executed directly after the web service is developed but even later, which has to be considered in our model (Modeling Issue 1).

2. Revenues: Many financial option pricing models assume that revenues of IT investments follow a stochastic process (i.e., a sequence of random variables corresponding to various times) called Geometric Brownian Motion (GBM) [9, 34, 76, 79]. The random variables' probability distribution collected in a GBM is lognormal at any point in time and mean and variance of the random variables are linearly increasing in time (given a strictly positive drift parameter; cf., [36], p. 284). This implies that mean and variance of GBM go to infinity as time goes by (cf., [17], p. 101). Applying this assumption to our case would imply that the revenues from selling the use of a web service to other firms are not limited [57]. While this may be an appropriate assumption to make in the speculative setting of a stock market (cf., [28]), it obviously does not apply to revenues that result from selling the use of web services. IT applications and especially web services are typically subject to a life cycle $[16,30,51]$. This implies that the mean of the revenues typically increases only up to a certain point 
in time and subsequently decreases to the end of the life cycle (cf., [60, 71]). As several web services with similar functionalities are usually provided on the web service market, also market laws hinder revenues to go to infinity. Hence, a firm has to validate which stochastic process fits to model revenues from selling the use of web services on the web service market. Consequently, we have to choose a valid stochastic process that represents the characteristics of these revenues in our model (Modeling Issue 2).

3. Costs: To estimate IT investment costs, several cost estimation techniques are proposed in literature (see $[15,38]$ for an overview). In general, these techniques can be used to estimate the deterministic strike price as assumed in the Black-Scholes Model or the Binomial Model. However, the assumption of a deterministic strike price is criticized (e.g., [3, 6, 7, 60, 71]) as IT investment costs are often subject to different risk factors. In our case, an example for a risk factor that affects the strike price is the fluctuating availability of technical skills (cf., $[60,71])$. This may lead to an unexpected increase in additional development costs (e.g., costs for digital APIs and costs for different web service versions) or to an unexpected change in hosting costs (e.g., costs for additional investments in security measures; cf., [71]). Hence, it is not reasonable to assume the strike price to be certain and known but the associated risks have to be taken into account. Such risks are typically measured based on risk analysis techniques such as the probabilistic sum (e.g., [86]), sensitivity analysis (e.g., [15, 48]), or probabilistic scenario analysis (e.g., [48, 90]). Based on these techniques, possible (but risky) events are identified and their impact on the IT investment costs are estimated (cf., [64]). These events and their impact in combination with associated probabilities of occurrence can be used to calculate the variance of the resulting random variable representing the risk of IT investment costs (cf., [90]). However, as the risks associated with future cash flows may change over time (cf., [48]), it is not sufficient to use a static random variable. Instead, to consider the time dependency of mean and variance of a random variable, the strike price has to follow a stochastic process that considers the evolution of the costs for exposing a web service over time (Modeling Issue 3).

4. Replicating Portfolio: Financial option pricing models assume that all risks associated with the underlying asset are assumed to be hedgeable (cf., [36]). To be able to continuously hedge the risks of the option, an underlying asset is required to be traded on the market. As real investments (like IT 
investments) are usually not traded, researchers (e.g., [8, 39, 43, 60, 71]) have raised concerns about the existence of a corresponding market and the possibility to create a replicating portfolio for IT investments. However, Sick ([74], p. 652) argues that the underlying asset does not have to be traded if any traded asset ("twin security"; cf., [80]) exists that perfectly correlates to the underlying asset (i.e., one that duplicates the cash flows of the web service). Hence, if it is possible to identify a "twin security”, the risk-neutral valuation concept of financial option pricing models seems to be appropriate. In our make-or-buy decision problem context, there obviously exists at least one functional similar web service on the web service market - representing the "buy decision" - that can be used as a "twin security". This web service can be used to duplicate the revenues and thereby to hedge the risks associated with the revenues (e.g., fluctuations in demand for the web service). However, this "twin security" cannot be used to duplicate, for instance, the additional development costs or the hosting costs because these cost categories are typically idiosyncratic (cf., [3, 80]). Consequently, our model has to consider that the risks associated with costs for exposing a web service cannot be hedged and have to be considered in decision-making (Modeling Issue 4).

Concluding, it appears inappropriate to merely applying financial option pricing models to value the option to expose and sell the use of a web service on the web service market due to the afore-mentioned criticism. We identified four modeling issues, which have to be addressed in developing an approach for the valuation of such a sell option. These Modeling Issues are summarized in the following.

- Modeling Issue 1 (Option Runtime): The sell option can be executed directly after the web service is developed or even later.

- Modeling Issue 2 (Revenues): Revenues from selling the use of a web service have to follow a stochastic process that represents the characteristics of the considered web service.

- Modeling Issue 3 (Costs): Costs for exposing a web service on the web service market are risky and have to follow a stochastic process that represents the characteristics of the considered web service.

- Modeling Issue 4 (Replicating Portfolio): Risks associated with the revenues from selling the use of a web service can be hedged by a functional similar web service from the web service market but risks associated with the costs from exposing a web service cannot. 


\section{Real option analysis approach to value the sell option}

Based on the four Modeling Issues above, we develop a real option analysis approach to consider the characteristics of web services when valuing the option to expose and sell the use of a web service on the web service market. In this section, we introduce the notation and the assumptions of our real option analysis approach and present a simulation model to value the sell option.

\subsection{Notation and assumptions}

A non-software firm decides in $t=0$, whether to develop a web service internally (make-decision) or to obtain it from the web service market (buy-decision). Using a traditional make-or-buy approach a firm would compare the internal development costs for the web service $C_{M}$ and the costs for purchasing the web service $C_{B}$ and decide for the better alternative. ${ }^{2}$

If a firm decides to develop a web service internally, it can further choose after the internal development of the web service in $t=T$, if it executes the option to expose and sell the use of this web service on the web service market. This opportunity represents a long position in a call option (cf., [36], p. 197), because the firm owns the option and has the right, but not the obligation, to undertake a further investment to expose the web service and sell its use. This call option can be executed as soon as the internal development of the web service is completed in $t=\underline{T}$ and until the option does not exist anymore in $t=\bar{T}$ (e.g., when there is no more demand for the use of the web service due to an outdated technology, changing business requirements, or changing regulatory requirements). Consequently, we make the following assumption and thereby address Modeling Issue 1:

Assumption 1 (Option Runtime): A decision maker can execute the sell option as soon as the internal development of the web service is completed and until the option does not exist anymore: $T \in[\underline{T}, \bar{T}])$.

In $t=T$, the firm executes the sell option if and only if the additional revenues (discounted cashinflows) from selling the use of the web service are higher than the additional costs (discounted cash-

\footnotetext{
${ }^{2}$ The internal use of a web service usually causes a similar amount of revenues regardless of whether a firm develops or obtains it (due to equal functionalities). Consequently, revenues have no (decision-relevant) effect on the make-or-buy decision, which is why revenues from the internal use remain unconsidered in traditional make-or-buy approaches (cf., [20, 87]).
} 
outflows) from exposing the web service which is equivalent to the payoff structure of a long position in a call option (cf., [36], p. 198]. The firm further chooses to execute the option (i.e., the option runtime) $T \in$ $[\underline{T}, \bar{T}]$ at the instant when the difference between the revenues and the costs are expected to be maximal.

The revenues from selling the use of the web service $S_{t}$ result from the web service's price and demand on the web service market. The web service market is characterized by price competition (e.g., Bertrand competition) as the production capacity (i.e., the number of supplied uses of a web service) is flexible as for all digital goods. Consequently, the firm sets a profit maximizing price in $t=0$ for a given market structure. The resulting demand from the determined price is known in $t=0$, but may change and is risky over time (between $t=0$ and $t=T$ ) resulting from the life cycle of the considered web service (cf., Modeling Issue 2). Consequently, we have to choose a stochastic process to represent the demand fluctuation over time. For similar purposes Ewald and Yang [28] and Sarkar [67] proposes geometric mean reversion (GMR). GMR has the property that demand and consequently revenues may increase but revert to a certain mean and its growth of variance diminishes over time (cf., $[28,75])$. Thus, to address Modeling Issue 2, we make the following assumption:

Assumption 2 (Revenues): The revenues $S_{t}$ from selling the use of a web service follow a GMR over time: $\frac{d S_{t}}{S_{t}}=\alpha\left(\theta-S_{t}\right) d t+\sigma_{S} d W_{t}$.

In Assumption 2, $\alpha$ represents the speed of mean reversion, and thus the velocity of $S_{t}$ being dragged back over time to its long-term mean. $\theta$ represents the total revenues that a firm expects to be achieved by selling a web service on the web service market during its life cycle. The standard deviation $\sigma_{S}$ represents the revenue's risk resulting from demand fluctuations on the use of the considered web service.

Providing a web service on the web service market also yields costs for exposing the web service $X_{t}$ such as additional development costs, hosting costs, marketing costs, etc. (cf. Table 1). In Modeling Issue 3, we argued for risky costs that follow a stochastic process. Some authors of real option analysis literature who also criticize a known and certain strike price suggest that IT investment costs should follow a GBM (e.g., [6, 26, 44, 45, 79]). This implies that the costs are not limited which is consistent to a study of Bloch et al. [14] who found that around half of all IT investments massively blow their budget. Consequently, we follow the prevailing opinion in literature and state the following assumption: 
Assumption 3 (Costs): The costs $X_{t}$ for exposing a web service follow a GBM over time: $\frac{d X_{t}}{X_{t}}=$ $\mu_{X} d t+\sigma_{X} d W_{t}$

In Assumption 3, $\sigma_{X}$ represents the square root of the instantaneous variance of $X_{t}, \mu_{X}$ the drift rate of $X_{t}$, and $W_{t}$ the Wiener process driving the costs over time (cf., [36], p. 284).

As already discussed in Modeling Issue 4, functional similar web services obviously exist on the web service market that can be used to duplicate the revenues and consequently to build a replicating portfolio. However, the risks associated with the costs for exposing the web service are idiosyncratic and thus cannot be hedged. Consequently, we state the following assumption concerning the duplication of revenues and costs addressing Modeling Issue 4:

Assumption 4 (Replicating Portfolio): A replicating portfolio to hedge the risks of the revenues from selling the use of the internal web service can be built through functional equivalent web services on the web service market. A replicating portfolio to hedge the risks of the costs for exposing a web service on the web service market cannot be built.

Consequently, a firm has to consider unhedgeable risks associated with the costs for exposing a web service according to the risk preference of the decision maker. We follow the approach suggested by Benaroch and Kauffman [8] and use a risk adjustment rate $\delta$ that is subtracted from the risk-free interest rate $r$ when discounting future costs (cash-outflows). Thereby, for risk averse decision makers $\delta$ has an upper bound being equal to the risk-free interest rate $r$. A risk adjustment rate of $\delta=0$ represents a riskneutral decision maker and a risk adjustment rate of $\delta<0$ represents a risk seeking decision maker. One possibility to determine the risk adjustment rate $\delta$ is to set it equal to a firm's weighted cost of capital (cf., $[56,58,73])$.

Based on this set of assumptions, it is no longer possible to use financial option pricing models such as the Black-Scholes Model, the Binomial Model, or the Margrabe Model and to calculate a closed-form solution for the value of the sell option. Hence, we present a simulation model to value the sell option and to support make-or-buy decisions on web services. 


\subsection{Simulation model}

In accordance to Assumption 2, the revenues $S_{t}$ have to follow a $\mathrm{GMR}^{3}$ over time. However, as it is not possible to calculate the realizations $S_{T, i}$ of a GMR in a closed form, we use a process with similar properties called Exponential Mean Reversion (EMR) that is frequently used to approximate GMR in literature (e.g., [19]). EMR is defined by equation (1):

$$
\frac{d S_{t}}{S_{t}}=\alpha\left(\theta-\ln \left(S_{t}\right)\right) d t+\sigma_{S} d W_{t}
$$

To calculate a realization $S_{T, i}$ of the revenues following EMR we use equation (2) (cf., [19]):

$$
S_{T, i}=\exp \left\{\ln \left(S_{0}\right) e^{-\alpha T}+\left(\theta-\frac{\sigma_{S}^{2}}{4 \alpha}\right)\left(1-e^{-\alpha T}\right)+\sqrt{\left(1-e^{-2 \alpha T}\right) \frac{\sigma_{S}^{2}}{2 \alpha}} \varepsilon_{i}\right\}
$$

Here, $\varepsilon_{i}$ is a realization of a standard normally distributed random variable.

In accordance to Assumption 3 the costs $X_{t}$ follow a GBM ${ }^{4}$ over time. To calculate a realization $X_{T, i}$ of the costs following GBM, we use equation (3) (cf., [19]):

$$
X_{T, i}=X_{0} \cdot \exp \left\{\left(r-\frac{1}{2} \sigma_{X}^{2}\right) T+\sigma_{X}^{2} \sqrt{T} \varepsilon_{i}\right\}
$$

Based on the calculated realizations of $S_{T, i}$ using equation (2) and $X_{T, i}$ using equation (3), we calculate the option value $O$ for a specific option runtime $T \in[\underline{T}, \bar{T}]$ by equation (4):

$$
O=\frac{1}{n} \sum_{i=1}^{n} \max \left(e^{-r T} S_{T, i}-e^{-(r-\delta) T} X_{T, i} ; 0\right)
$$

Equation (4) defines the value of the option in $t=0$ from exposing and selling the use of a web service in $t=T$ to be the average of the $n$ realizations of the maximum of either (a) the difference between the present value of the revenues $\left(e^{-r T} S_{T, i}\right)$ and the risk-adjusted present value of the costs $\left(e^{-(r-\delta) T} X_{T, i}\right)$ or (b) zero. Using equation (5) we calculate a decision value $D$.

\footnotetext{
${ }^{3}$ In cases where GMR does not adequately represent the evolution of the revenues $S_{t}$, equation (2) could easily be adapted to other stochastic processes or techniques. The remaining simulation model can be applied as before.

${ }^{4}$ In cases where GBM does not adequately represent the evolution of the costs $X_{t}$, equation (3) could easily be adapted to other stochastic processes or techniques. The remaining simulation model can be applied as before.
} 


$$
D=-C_{M}+O+C_{B}
$$

If $D$ is greater than zero, a firm develops the web service internally or otherwise buys the web service from an external service provider. Thus, existing make-or-buy approaches (e.g., [78]) can be used to determine $C_{M}$ and $C_{B}$ and can be enhanced by our approach to value the sell option.

\section{Application: Real-world example or the MCRB}

In this section, we demonstrate the applicability of our approach using the real-world example of the MCRB introduced in Subsection 3.2. Thereby, we answer the following questions:

- How may the required input parameters (e.g., revenues, costs) be estimated?

- How may the sell option change traditional make-or-buy-decisions?

- What is the optimal point in time (i.e., option runtime) to execute the sell option for the MCRB?

\subsection{Estimation of the input data}

In order to estimate the effort involved in developing the web services, the MCRB classifies web services according their complexity and assigns a specific development effort to each complexity class. This development effort is expressed in number of person days (PDs) and covers effort for project management, analysis and design, implementation, test, and integration, as well as overheads. For the required overhaul of existing web services and the development of the three new business services including multiple web services, the MCRB estimates an effort of 1500 PDs. As the MCRB calculates with average costs of 1000 EUR per PD, we obtain total costs of $C_{M}=1.5 M E U R$ to develop the required business services in-house (make decision).

Alternatively, the MCRB could purchase a web service-based solution provided by the rating agency Schufa that includes the functionalities that are required by the MCRB. The MCRB negotiated with Schufa a fixed price of $C_{B}=1.25 \mathrm{MEUR}$ for using this web service-based solution for 4 years.

Traditionally, the MCRB would compare the internal development costs $\left(C_{M}=1.5 \mathrm{MEUR}\right)$ with the costs of buying the externally provided solution $\left(C_{B}=1.25 \mathrm{MEUR}\right)$ to make its make-or-buy decision. This approach would clearly suggest that the MCRB should buy the externally provided solution $\left(C_{B}<\right.$ $\left.C_{M}\right)$. However, due to the option of exposing and selling the use of their internal web services via external 
distribution frontends (cf., Fig. 1), the executives of MCRB would like to evaluate the make-decision in more detail. The sell option can be executed at the earliest directly after completion of the internal web service development, which the MCRB estimated to be in $\underline{T}=1$ year, and at the latest before the web services would be deemed outdated due to new technologies, changing business requirements, or changing regulatory requirements, which is estimated to occur in $\bar{T}=4$ years. However, the MCRB would not be able to sell its web services without further investments required to expose the web services. ${ }^{5}$ Some of these additional costs are detailed as follows:

- Costs for digital frontend interfaces: Loan models and conditions differ dependent on the channel from which a business service is used. To distinguish the channels, each web service request contains meta data including a channel tag that identifies the requesting channel. For external web service requests, the existing channel tags have to be extended.

- Costs for digital backend interfaces: External FSPs that want to use the business services of the MCRB may have different backend systems. To enable the web services to exchange data with other backend systems, their interfaces have to be extended or made more flexible.

- Costs for security measures: Granting access to the MCRBs' business services for external FSPs may raise security issues. To avoid security issues such as misuse of data, additional security measures such as firewalls or secure channels are required.

The additional costs for exposing the web services (especially from additional development costs for digital APIs and hosting costs for additional security measures) are estimated by the MCRB to reach approximately $X_{0}=0.9 M E U R$. We take these costs to be risky and to follow GBM (cf., discussion in Subsection 4.1). The drift parameter $\mu_{X}$ of GBM is estimated to be $1.5 \%$, which represents the fact that the additional and risky costs are more likely to increase over time. Additionally, we estimate the instantaneous variance $\sigma_{X}^{2}$ of GBM according to the idea of Aubert et al. [4]. Hence, we define several independent scenarios and estimate their probability of occurrence based on historical data for this cost component.

\footnotetext{
${ }^{5}$ To consistently value the revenues from selling the use of the internal web services and the corresponding costs for exposing the web service, we discount both values to the instant $t=T$. Thus, the fact that the majority of the costs are realized before the realization of revenues is considered when applying the model.
} 
Based on these scenarios and their probability of occurrence, we build a decision tree and use the maximum likelihood method described by Eliason [27] to estimate the instantaneous variance $\sigma_{X}^{2}=6.25 \%$.

The MCRB only executes the option to sell the use of their business services in $t=T$ if the revenues from selling exceed the costs for exposing the web services. To estimate customer demand in $t=0$, we use available historical data of the rating agency Schufa (cf., $[68,69])$ and calculate the average of the signed consumer loan contracts per year in Germany to be approximately 7.2 Million contracts (cf., [68, 69]). The MCRB further interviewed FSPs on their willingness to use its business services for a price of 2.20 EUR per signed loan contract (price that the MCRB sets for using their business services). Two of the interviewed FSPs were interested in taking the offer. Based on their market shares over recent years, we are able to conservatively estimate the expected revenues from selling the web services on the web service market over a planning horizon of four years to be $S_{0}=1.28 \mathrm{M} \mathrm{EUR}$.

Additionally, we set the long-term mean $\theta$ equal to the estimated revenues in $t=0$ (i.e., $\theta=S_{0}$ ) and set the mean reversion speed $\alpha$ to $0.4{ }^{6}$ To calculate the revenues' volatility of $\sigma_{S}=16.88 \%$ we use the same historical data from the rating agency Schufa (cf., [68, 69]) and an approach to empirically estimate this volatility (cf., [36]). For our calculations, we use a risk-free rate $r$ of $3 \%$.

To estimate the risk adjustment rate $\delta$ we analyzed the risk preference of the MCRB. We started by confronting the executives with two hypothetical investments, whereupon investment one has a certain value, and investment two having the same, but risky value. All executives preferred the certain investment why we concluded that the MCRB is risk averse. Subsequently, we applied empirical utility assessment techniques (e.g., [29]) and confronted the executives of the MCRB again with two hypothetical investments where one of them has a certain and one a risky value. Then, we altered the value of the risky investment until the MCRB was indifferent between the two investments. Based on the behavior of the MCRB, we could determine a risk adjustment rate of $\delta=2.0 \%$. The input data for applying our approach to the real world example are summarized in Table 2.

\footnotetext{
${ }^{6}$ The mean reversion speed can easily be visualized with the so-called concept of process half-life. This concept gives the average time revenues need to revert to half of their distance from the long-term mean $\theta$. It is calculated as $H=\ln (2) / \alpha$ and for the case of $\alpha=0.4$ the process reverts to half its distance from the long-term mean in $H=1.73$ years.
} 


\begin{tabular}{|c|c|c|c|}
\hline Parameter & Definition & $\begin{array}{c}\text { Parameterization } \\
\text { in the MCRB's example }\end{array}$ & $\begin{array}{l}\text { (Expected) } \\
\text { Value }\end{array}$ \\
\hline \multicolumn{4}{|c|}{ Input } \\
\hline \multirow[t]{5}{*}{$S_{0}(=\theta)$} & $\begin{array}{r}\text { Expected revenues in EUR } \\
\text { (Long-term mean of the GMR) }\end{array}$ & $\begin{array}{l}\text { Calculated using the } \\
\text { input parameters below }\end{array}$ & $1,280,448$ \\
\hline & $\begin{array}{l}\text { Average number of loan contracts in } \\
\text { Germany per year }\end{array}$ & $\begin{array}{l}\text { Estimated based on Schufa's } \\
\text { historical data (cf., }[68,69])\end{array}$ & $7,275,273$ \\
\hline & $\begin{array}{l}\text { Planning horizon for using the } \\
\text { business services (in years) }\end{array}$ & $\begin{array}{l}\text { Estimated based on typical } \\
\text { technology life cycles }\end{array}$ & 4 \\
\hline & $\begin{array}{l}\text { Market share of potential customers } \\
\text { (other FSPs) }\end{array}$ & $\begin{array}{l}\text { Estimated based on current } \\
\text { market shares }\end{array}$ & $2 \%$ \\
\hline & $\begin{array}{c}\text { Price per signed loan contract } \\
\text { (EUR) for using the business services }\end{array}$ & $\begin{array}{l}\text { Set by MCRB based on a profit } \\
\text { maximization calculus }\end{array}$ & 2.20 \\
\hline$\sigma_{S}$ & $\begin{array}{l}\text { Volatility of revenues based on } \\
\text { fluctuations in customer demand }\end{array}$ & $\begin{array}{l}\text { Calculated using statistical data } \\
\text { from Schufa (cf., }[68,69])\end{array}$ & $16.88 \%$ \\
\hline$\alpha$ & Mean reversion speed & $\begin{array}{c}\text { Assumption based on } \\
\text { discussions with the MCRB }\end{array}$ & 0.4 \\
\hline$X_{0}$ & Expected costs (EUR) & $\begin{array}{c}\text { Estimated based on } \\
\text { internal cost estimations }\end{array}$ & 900,000 \\
\hline$\mu_{X}$ & Drift rate of $X_{T}$ & $\begin{array}{c}\text { Assumption based on } \\
\text { discussion with the MCRB }\end{array}$ & $1.5 \%$ \\
\hline$\overline{\sigma_{X}^{2}}$ & $\begin{array}{l}\text { Instantaneous variance } \\
\text { of the costs }\end{array}$ & $\begin{array}{c}\text { Estimated based on } \\
\text { a scenario analysis (cf., [4]) }\end{array}$ & $6.25 \%$ \\
\hline$r$ & Risk-free discount rate & $\begin{array}{c}\text { Assumption based on } \\
\text { market data from the year } 2014\end{array}$ & $3 \%$ \\
\hline$\delta$ & Risk adjustment rate & Given as input data by MCRB & $2 \%$ \\
\hline$T \in[\underline{T}, \bar{T}]$ & Option runtime & Given as input data by MCRB & {$[1 ; 4]$} \\
\hline
\end{tabular}

\subsection{Application of the real option approach}

Based on the input data mentioned above, we applied our approach to the real-world example of the MCRB. Therefore, we draw $n=100,000$ realizations $\varepsilon_{i}$ of a standard normal distribution by means of a random number generator and calculate the according realizations of the revenues $S_{T, i}$ following GMR (Modeling Issue 2) using equation (2) and the costs $X_{T, i}$ following GBM (Modeling Issue 3 ) using equation (3) with $i \in\{1,2, \ldots, n\}$. Afterwards, we use equation (4) to value the sell option $O$ considering unhedgeable risks associated with the costs (Modeling Issue 4). We additionally consider Modeling Issue 1 by 
calculating the option values for different option runtimes $T \in[1 ; 4]$ keeping the revenues $S_{0}$ constant. $^{7}$

Table 3 illustrates the resulting option values for different option runtimes.

Table 3. Option values for different option runtimes.

\begin{tabular}{|c|c|c|c|c|c|c|c|}
\hline $\mathrm{T}$ & 1 & 1.5 & 2 & 2.5 & 3 & 3.5 & 4 \\
\hline 0 & 364,782 & 359,978 & 357,082 & 352,463 & 351,601 & 346,973 & 344,015 \\
\hline
\end{tabular}

By using equation (5) we further calculate the decision values for the different option runtimes depicted in Table 4.

\section{Table 4. Decision values for different option runtimes.}

\begin{tabular}{|c|c|c|c|c|c|r|r|}
\hline $\mathrm{T}$ & 1 & 1.5 & 2 & 2.5 & 3 & 3.5 & 4 \\
\hline$D$ & 114,782 & 109,978 & 107,082 & 102,463 & 101,601 & 96,973 & 94,015 \\
\hline
\end{tabular}

Since all decision values for the different option runtimes are positive, the MCRB would develop the web service internally based on our approach. This differs from the decision the MCRB would have made without considering the sell option. Hence, the option to expose and sell the use of the internal web service on the web service market can have a considerable impact on traditional make-or-buy decisions and makes the internal development of web services more attractive for non-software firms.

Considering Table 3, we further see that the option value decreases with an increasing option runtime. In the real option theory, the so-called "Greek letters" measure the sensitivity of the option value to a change in the underlying parameters (cf., [36], p. 377). The Greek letter "theta” measures the sensitivity of the option value to a changing option runtime and defines that the option value increases in the option runtime (cf., [36], pp. 387). This results from the increasing time value of the option. Thus, our result contradicts real option theory. However, our results are reasonable in the context of web services and most

\footnotetext{
${ }^{7}$ In reality, an increasing option runtime (i.e., the later the use of the web service is sold on the web service market) usually results in lower revenues $S_{0}$. This can be argued by the fact that the time when a web service is outdated is fixed and consequently a delay of executing the option shortens the period where the firm can realize revenues from selling the web service on the market (cf., [71], p. 59). By holding the revenues $S_{0}$ constant, we explicitly want to analyze the sole effect of the option runtime on the option value and do not include the effect of decreasing revenues due to a later execution of the option. Considering decreasing revenues with an increasing option runtime would result in even lower option values (cf., [35], pp. 357).
} 
IT investments that are subject to a specific life cycle. This becomes obvious as delays in the underlying IT investment (in our case the internal development of the web service) or intentionally postponing the execution of the sell option should not influence the option value in a way that it can continuously grow in time (even grow to infinity). Otherwise, non-software firms with inefficient and slow software development processes would gain more economic value compared to firms that are efficient in software development. In general, the increasing time value of an option is a result of modeling revenues to follow a GBM having a linearly increasing mean and variance and the costs to be known and certain (cf., the discussion in Subsection 3.3 concerning Modeling Issue 2 and Modeling Issue 3). In our set of modeling issues and assumptions in the Sections 3.3 and 4.1, we argue for revenues that follow a GMR and costs that are uncertain and follow GBM to better represent the characteristics of web services. As GMR reverts to a certain mean and have a diminishing growth of variance, mean, and variance of the costs increase faster than mean and variance of revenues. Consequently, the difference between revenues and costs which basically represents the option value decreases in the option runtime. This supports the intuition that the time value of the option to expose and sell the use of the web services decreases in the duration of the internal development of the web service and consequently with a lower time-to-market.

\section{Discussion}

In this section, we validate our approach by empirically testing the assumptions and the results and by applying a sensitivity analysis. Finally, we discuss managerial implications and limitations.

\subsection{Validation of the assumptions}

In order to validate whether our assumptions represent the characteristics of web services, we interviewed five decision makers from industry using a semi-structured interview approach. This included an associate of an IT consulting company, a senior ERP architect of a multinational engineering and electronics company, a freelancer who works for different clients in various IT projects, a consultant of a business consulting company, and the financial manager of IT strategies and corporate IT of a global IT services provider. This set of interviewees results in a so-called "triangulation of subjects" due to the fact that they occupy different functions in different companies (cf., [66]). Every interview took about an hour. We structured the interviews in compliance to the topics given by our four assumptions: 1) Option Runtime,

2) Revenues, 3) Costs, 4) Market Completeness. We sent out the interview guidelines to the interviewees 
prior to the interviews. The interviews were all audio-taped and subsequently transcribed. With the help of notes that were taken during the interviews, written summaries were produced directly after the interviews. Using the transcripts and summaries, we finally conducted a qualitative content analysis (cf., [63]), which resulted in insights from practice regarding our assumptions. We briefly summarize the results in the following.

1) Option Runtime: All five interviewees considered that it is unrealistic that IT projects and consequently the development of web service are completed ahead of schedule. A reason given by one interviewee is that "IT projects are never completed earlier as initially planned because people make use of the estimated time, even if they could have completed earlier". Moreover, all interviewees stated that if the option runtime increases, the revenues are more likely to remain constant or even decrease, rather than increase because of technological life cycles (see also next paragraph). These statements support our Assumption 1 that there is a minimal option runtime $\underline{T}$ (i.e., when the development of the web service is completed) and a maximal option runtime $\bar{T}$ (i.e., when the web services revenues decrease to a point that the option does not exist anymore) for the option to sell the use of a web service on the web service market.

2) Revenues: As already discussed in the last paragraph, all interviewees stated that if the determined option runtime increases, the revenues are more likely to remain constant or even decrease, rather than increase. This was exemplified by one interviewee who mentioned that "the longer we take to rollout an IT project the lower the market potentials usually will be" (i.e., Time-to-Market effects). Two interviewees stated that revenues are likely to increase over time if the respective technology is in a very early stage of development. Specifically, it was mentioned that "if the used technology is in a very early development stage and we increase the runtime, the new functionalities have more time to mature and consequently revenues are likely to increase". Contrarily, they argued that revenues for mature technologies decrease over time. This supports the argument that web services are subject to a technology life cycle and supports our Assumption 2 that revenues follow GMR.

To further support the application of GMR for the revenues in our real world example, we validated the GMR using a data set from the Deutsche Bundesbank [23] including data of the monthly volume of signed consumer loan contracts in EUR from January 2003 until December 2014. We use this data set in combination with data about the average volume per loan contract (cf., $[68,69])$ as an indicator for the 
development of the monthly number of signed consumer loan contracts. To parameterize the GMR, we used the volumes of the months January 2003 to December 2013. Based on this parameterized function, we forecasted the volumes for January 2014 to December 2014. To get a robust forecast, we did this 10,000 times for each month and calculated the mean values for each month, respectively. Fig. 3 illustrates the forecast mean values and the actual volumes from the dataset.

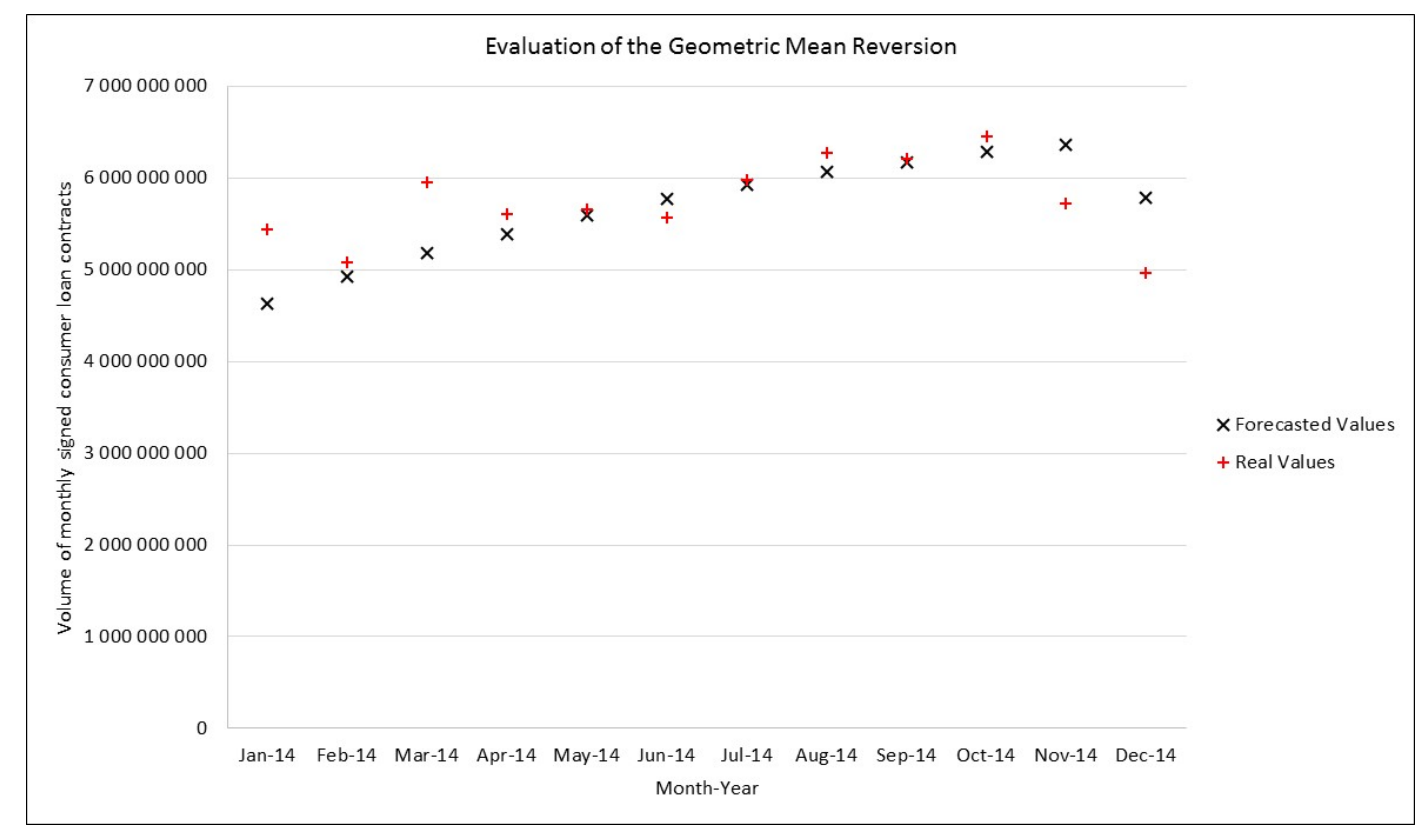

Fig. 3. Validation of the GMR.

Based on these data we calculated a mean absolute error of $6.2 \%$ of the forecasted time series. Lewis [50] refers to the forecasting ability of a method as being very good if the mean absolute error is equal or less than $10 \%$, good if it is equal or less than $20 \%$, and if it is higher than $30 \%$ the method cannot be used. According to that, the calculated absolute error indicates that the GMR is a "very good" descriptor for the future development of revenues from selling the use of a web service on the web service market (cf., [50]).

3) Costs: All interviewees stated that costs for software development are risky. Examples the interviewees mentioned were that "a resource can fail and need to be replaced immediately by a more expensive one". Moreover, the interviewees mentioned that occasionally an unplanned but substantial increase of the costs happens in IT projects. An example given by one interviewee was that "we often identify new requirements during the runtime of an IT project, which leads to an extended scope that substantially increases the costs". This supports our Assumption 3 that costs are risky and follow a GBM. 
4) Replicating Portfolio: All interviewees agreed that the majority of the risk associated with the costs of an IT project is idiosyncratic and cannot be hedged. Examples for idiosyncratic risks are a shortage of available resource (e.g., software engineering experts are staffed on other projects), a change in the requirements, or externally driven risk factors such as changing laws. This supports our Assumption A4 that risks associated with the costs for selling the use of a web service cannot be hedged.

These results support that our assumptions offer an adequate representation of the characteristics of web services.

\subsection{Validation of the results}

To validate the results of our approach, we conducted an interview with an IT executive of the MCRB to analyze to what extent our results comply with the realized results at the MCRB. We structured the interview questions in Decision, Costs, and Revenues. The questions, model results, and the realized results (answers of the IT executive) are illustrated in Table 5 and shortened to the core statements. 


\begin{tabular}{|c|c|c|}
\hline \multicolumn{3}{|c|}{ Table 5. Comparison of the model results and the realized results at MCRB. } \\
\hline \multicolumn{3}{|c|}{ Comparison model results vs. realized results } \\
\hline Interview questions & Model results & $\begin{array}{l}\text { Realized results (interview answers of the } \\
\text { IT executive of the MCRB) }\end{array}$ \\
\hline \multicolumn{3}{|c|}{ Decision } \\
\hline $\begin{array}{l}\text { Did you develop the } \\
\text { web services internally or } \\
\text { did you purchase the } \\
\text { standard solution? }\end{array}$ & $\begin{array}{l}\text { Based on the model } \\
\text { results, the MCRB should } \\
\text { develop the web services } \\
\text { internally when considering } \\
\text { the sell option. }\end{array}$ & "We developed the web services internally." \\
\hline $\begin{array}{l}\text { Did you expose and } \\
\text { sell the use of the web } \\
\text { services on the web } \\
\text { service market? }\end{array}$ & $\begin{array}{l}\text { Our model suggests to } \\
\text { expose and sell the use of the } \\
\text { internal web services. }\end{array}$ & $\begin{array}{l}\text { "Yes, our web services are used by several } \\
\text { firms to support their sales processes for } \\
\text { consumer loan contracts. In addition to the two } \\
\text { FSPs, a firm which sells used cars over the } \\
\text { internet, and another firm which sells coffee and } \\
\text { home appliances use our web services as well to } \\
\text { cross-sell consumer loans." }\end{array}$ \\
\hline \multicolumn{3}{|c|}{ Costs } \\
\hline $\begin{array}{l}\text { Did the actual costs for } \\
\text { developing the web } \\
\text { services internally deviate } \\
\text { from the estimated costs? }\end{array}$ & $\begin{array}{l}\text { We estimated the internal } \\
\text { development costs } C_{M} \text { to be } \\
\text { 1.5 M EUR. }\end{array}$ & $\begin{array}{c}\text { "The realized development costs for the web } \\
\text { services were slightly lower than our planned } \\
\text { numbers. We did not exceed budget constraints } \\
\text { in this project." }\end{array}$ \\
\hline $\begin{array}{l}\text { Did the actual costs for } \\
\text { exposing the web services } \\
\text { deviate from the estimated } \\
\text { costs? }\end{array}$ & $\begin{array}{l}\text { We estimated the costs } X_{0} \\
\text { to be } 0.9 \mathrm{M} \text { EUR. }\end{array}$ & $\begin{array}{c}\text { "The realized costs for exposing the web } \\
\text { services were slightly lower than our planned } \\
\text { numbers. We did not exceed budget constraints } \\
\text { in this project." }\end{array}$ \\
\hline \multicolumn{3}{|c|}{ Revenues } \\
\hline $\begin{array}{l}\text { Did the actual } \\
\text { revenues from selling the } \\
\text { use of the web services on } \\
\text { the web service market } \\
\text { deviate from the estimated } \\
\text { revenues? }\end{array}$ & $\begin{array}{l}\text { We estimated the } \\
\text { revenues } S_{0} \text { from selling the } \\
\text { use of the web services on the } \\
\text { web service market to be } \\
1.28 \mathrm{M} \text { EUR based on two } \\
\text { FSPs that are interested to use } \\
\text { the web services. }\end{array}$ & $\begin{array}{c}\text { "As our web services are used by more firms } \\
\text { than expected, the revenues are higher than } \\
\text { initially planned." }\end{array}$ \\
\hline
\end{tabular}

The results of the interview show that our estimations of the input data were conservative as the actual values for all cost components were slightly lower than the estimated values. This means that the project as a whole did not exceed the budget constraint. Moreover, the revenues were underestimated in our model because we only considered two firms which were already willing to use the developed web services in $t=0$. Thus, the value of the make decision was actually higher than the value we calculated with our model. This underlines the importance of enhancing traditional make-or-buy approaches by the sell option, 
as the additional value from selling the use of internal web services would not be considered (before and after the decision) by applying a traditional make-or-buy approach.

\subsection{Sensitivity analysis}

Estimation techniques for the input data may contain the possibility of error of judgment. For instance, estimations based on historical data might not be a good estimator for future developments and executives might not have enough information to estimate the exact probabilities or outcomes. To evaluate the robustness of our results we conduct a sensitivity analysis. Therefore, we decrease and increase each input parameter value by $10 \%$, ceteris paribus, and analyze the impact on the results of our approach discussed in Section 5.2. Table 6 reports the results of the sensitivity analysis where we use the initial values from the case with an option runtime $T=1$, as this is the optimal option runtime for the MCRB. The first column in Table 6 shows the initial values of the input data. Each row of Table 6 contains two sub-rows. The first (second) sub-row shows the results of the sensitivity analysis if the input parameter value is decreased (increased) by $10 \%$ relative to the initial value.

\begin{tabular}{|c|c|c|c|c|}
\hline $\begin{array}{c}\text { Parameter original } \\
\text { values }\end{array}$ & Modified values & Option value & Decision value & Ex-ante decision \\
\hline \multicolumn{2}{|l|}{ Original approach } & 364,782 & 114,782 & Make \\
\hline \multirow{2}{*}{$\begin{array}{l}X_{0} \\
900,000 \text { EUR }\end{array}$} & 810,000 EUR & 442,429 & 192,429 & Make \\
\hline & 990,000 EUR & 290,615 & 40,615 & Make \\
\hline \multirow{2}{*}{$\begin{array}{l}\sigma_{X} \\
25 \%\end{array}$} & $22.50 \%$ & 358,373 & 108,373 & Make \\
\hline & $27.50 \%$ & 367,914 & 117,914 & Make \\
\hline \multirow{2}{*}{$\begin{array}{l}\mu_{X} \\
1.5 \%\end{array}$} & $1.35 \%$ & 365,733 & 115,733 & Make \\
\hline & $1.65 \%$ & 361,579 & 111,579 & Make \\
\hline \multirow{2}{*}{$\begin{array}{l}S_{0} \\
1,280,448 \text { EUR }\end{array}$} & 1,152,403 EUR & 256,379 & 6,379 & Make \\
\hline & 1,408,493 EUR & 479,748 & 229,748 & Make \\
\hline \multirow{2}{*}{$\begin{array}{l}\sigma_{S} \\
16.88 \%\end{array}$} & $15.19 \%$ & 360,198 & 110,198 & Make \\
\hline & $18.57 \%$ & 367,899 & 117,899 & Make \\
\hline \multirow{2}{*}{$\begin{array}{l}\alpha \\
0.4\end{array}$} & 0.36 & 364,867 & 114,866 & Make \\
\hline & 0.44 & 363,797 & 113,797 & Make \\
\hline \multirow{2}{*}{$\begin{array}{l}\delta \\
2.0 \%\end{array}$} & $1.80 \%$ & 365,847 & 115,847 & Make \\
\hline & $2.20 \%$ & 362,655 & 112,655 & Make \\
\hline \multirow{2}{*}{$\begin{array}{l}C_{M} \\
1,500,000 \text { EUR }\end{array}$} & 1,350,000 EUR & 364,782 & 264,782 & Make \\
\hline & $1,650,000$ EUR & 364,782 & $\begin{array}{l}-35,218 \\
\end{array}$ & Buy \\
\hline \multirow{2}{*}{$\begin{array}{l}C_{B} \\
1,250,000 \text { EUR }\end{array}$} & 1,125,000 EUR & 364,782 & $-10,218$ & Buy \\
\hline & $1,375,000$ EUR & 364,782 & 239,782 & Make \\
\hline
\end{tabular}

The sensitivity analysis shows that for an increase and decrease of the input data by $10 \%$, ceteris paribus, the ex-ante decision mostly stays the same. Thus, for most of the input parameter values, it is not 
crucial if the MCRB estimates them slightly imprecisely in order to still arrive at a valid decision. However, the sensitivity analysis adds value to the ex-ante decision by identifying which input parameters are critical when estimating their values. In our case, the costs for developing the web service internally (i.e., $C_{M}$ ) and the costs for buying the web service (i.e., $C_{B}$ ) are the most critical input parameters, since a substantial overestimation of $C_{M}$ or a substantial underestimation of $C_{B}$ would lead to flawed investment decisions. This is even more pronounced when the risk-adjusted decision values are negative for these cases (buydecision). Thus, the MCRB should estimate these parameters carefully.

In an extended sensitivity analysis, we further calculated all option values depicted in Table 6 for a variety of option runtimes $T \in[1 ; 7]$. We additionally took extreme input parameter value constellations and calculated the respective option values for the same option runtimes $T \in[1 ; 7]$. We found that for all considered input parameter value constellations, the option value decreases in the option runtime considering the entire domain of option runtimes $T \in[1 ; 7]$. Consequently, our finding that it is preferable to execute the sell option as soon as possible after completion of the internal development of the web service does not only hold for the input parameter values of our case example but seems to hold for most input parameter value constellations.

\subsection{Managerial implications}

Nowadays, firms usually develop individualized web services that are used to execute core business processes in-house (make-decision; cf., [61]) and do not offer them on the web service market (selldecision) due to strategic reasons (cf., [47]). At the same time, they often outsource business processes (buy-decision) that "are standardized (commoditized), can precisely be defined, and may even be considered tedious, repetitive, and undesirable” ([20], p. 14). However, if the additional option to expose and sell the use of internal web services on the web service market is considered, it may become more attractive for some firms to realize standardized business processes in-house. An example is the online sales process of consumer loan contracts at a FSP (cf., Section 5), which would have been outsourced without considering the sell option enabled by the web service technology.

Additionally, a decision maker usually has the option to expose and sell the use of an internal web service directly after the web service is developed or even later. According to our results, it is not optimal to unnecessarily postpone the decision whether to expose and sell the use of the internal web services. 
Consequently, a decision maker should execute the sell option immediately after the internal development of the respective web service is completed.

\subsection{Limitations}

Although we illustrated the strength of our approach by applying and validating it in a real-world example, we also have to consider some limitations that may represent starting points for future research.

Parameterization: Although we presented an exemplified technique for the estimation of input parameters in our real-world example, the parameterization of our model is often based on historical data, experiences, and expert estimations. However, regardless of the quality of the estimation technique, errors may occur based on such data. To identify critical parameters, we conducted a sensitivity analysis. In our example, a deviation of $10 \%$ for each input parameter, all else being equal, would not have changed the resulting decision except for a substantial overestimation of the costs for developing the web service internally or a substantial underestimation of the costs for buying the web service externally. This illustrates the importance of sensitivity analyses to identify critical parameters for the make-or-buy decision, which decision makers who apply our model have to bear in mind. In addition, further research could focus on refining current estimation techniques.

Modeling: We assumed $C_{B}$ and $C_{M}$ to be certain, which seems to be questionable at least for $C_{M}$. However, assuming $C_{B}$ and $C_{M}$ to be risky has no bearing on the option value and should only be made if these cost components are deemed to be risky in our enhanced make-or-buy approach.

We argued that especially in our case, other web services that are offered on the market and provide similar functionalities like the underlying web service can be used as "twin securities" to build the required replicating portfolio and thus to hedge the risks of the revenues. However, if there are no twin securities on the web service market, it might still be possible to value the option by means of a traded financial asset or a portfolio of financial assets that perfectly correlate with the revenues of the underlying web service. However, a perfect hedge of risks associated with the revenues of selling a web service on the web service market seems to be unrealistic on the financial market as these risks are usually firm specific (e.g., unforeseen user acceptance) and the identification of a security that correlates highly but not perfectly is not sufficient to get a correct option value [35]. Consequently, if no continuously traded asset or portfolio 
of assets can be identified on the financial market that perfectly correlates with the revenues of the underlying web service unhedgeable risks of the revenues have to be taken into account according to the risk preference of the decision maker. The risks of the revenues of the underlying web service could be considered, for example, according to the idea of Benaroch and Kauffman [8], which we applied to consider the risks of the additional development and hosting costs.

We implicitly assume that revenues and costs are (statistically) independent. This seems to be reasonable for our example as the revenues from selling the use of the web service and the costs for exposing the web service are influenced by different risk factors and occur at different points in time. Revenues are not realized until the web services are exposed, and hence, after the occurrence of the corresponding costs. Also, revenues are influenced by risk factors like unforeseen market changes in demand that do not influence the costs. However, this is not generalizable for all kinds of IT investments as cases may exist where a statistical dependency and thus a positive or negative correlation between revenues and costs seems to be plausible. A positive (negative) correlation decreases (increases) the option value, as the probability of a high difference between revenues and costs will be lower (higher) (cf., [26, 79]). A decision maker has to be aware of these effects.

\section{Conclusion}

Due to the new phenomena of exposing and selling the use of web services, for instance, through digital APIs, non-software firms can provide access to and monetize their internal web services. Consequently, if a firm decides to develop a web service internally, it has the option to sell the use of this web service on the web service market. In this paper, we introduced an approach to enhance traditional make-or-buy decision-making approaches by this sell option and applied this approach in a real-world example of a FSP to demonstrate the implications on decision-making.

Our findings are that (I) the sell option has considerable impact on traditional make-or-buy decisions and makes the internal development of web services more attractive; (II) it is preferable to execute the sell option as soon as possible after completion of the internal development of the web service, even if it is possible to execute the sell option later. Especially, result (II) contradicts the well-known result from real 
option theory where a longer option runtime increases the option value (cf., [36], p. 387), but is a better representation for the underlying characteristics of web services that are subject to a life cycle.

We want to conclude by considering the generalizability of our approach. In our paper, we demonstrated the applicability of our approach for the valuation of web services which support consumer loan processes, since these web services have great re-use potential by other FSPs. By extension, our approach would be similarly applicable to others firms across a variety of branches as long as they fulfill the critical characteristic by which the web services are reusable by other firms. Furthermore, we expect our approach to be transferable to cloud services and digital goods that are traded on markets and accessible via Digital APIs. Thus, this approach seems to be suitable for the valuation of a wide range of IT services.

\section{ACKNOWLEDGMENTS}

The research was funded by the Austrian Science Fund (FWF) [P 23567-G11].

\section{REFERENCES}

[1] Akana (2016). Accessed 20.03.2016 at [https://akana.com/solution/monetize-your-digital-assets].

[2] K.A. Alam, R. Ahmad, A. Akhunzada, M.H.N.M. Nasir, S.U. Khan, Impact analysis and change propagation in service-oriented enterprises: a systematic review, Information Systems 54 (2015), 4373.

[3] G.N. Angelou, A.A. Economides, A decision analysis framework for prioritizing a portfolio of ICT infrastructure projects, IEEE Transactions on Engineering Management 55 (2008) 479-495.

[4] B.A. Aubert, M. Patry, S. Rivard, Assessing the risk of IT outsourcing, Proceedings of the 31st Annual Hawaii International Conference on System Sciences (1998) 685-692.

[5] L. Auer, SOA investment decision-making using real options analysis, International Journal of Services, Economics and Management 5 (2013) 21-40.

[6] I.R. Bardhan, S. Bagchi, R. Sougstad, Prioritizing a portfolio of information technology investment projects, Journal of Management Information Systems 21 (2004) 33-60

[7] M. Benaroch, R.J. Kauffman, A case for using real options pricing analysis to evaluate information technology project investments, Information Systems Research 10 (1999) 70-86.

[8] M. Benaroch, R.J. Kauffman, Justifying electronic banking network expansion using real options analysis, MIS Quarterly 24 (2000) 197-225.

[9] M. Benaroch, S. Shah, M. Jeffery, On the valuation of multistage information technology investments and embedding nested real options, Journal of Management Information Systems 23 (2006) 239-261.

[10] M. Benaroch, Q. Dai, R.J. Kauffman, Should we go our own way? Backsourcing flexibility in IT service contracts, Journal of Management Information Systems 26 (2010) 317-358.

[11] J.W.M. Bertrand, J.C. Fransoo, Modelling and simulation: operations management research methodologies using quantitative modeling, International Journal of Operations \& Production Management 22 (2002) 241-264.

[12] BIAN - Banking Industry Architecture Network, Mission Statement. Accessed 21.03.2016 at [https://bian.org/about-bian/mission-strategy/].

[13] F. Black, M. Scholes, The pricing of options and corporate liabilities, Journal of Political Economies 
81 (1973) 637-654.

[14] M. Bloch, S. Blumberg, J. Laartz, Delivering large-scale IT projects on time, on budget, and on value. McKinsey on Business Technology 27 (2012) 1-7.

[15] B. Boehm, C. Abts, S. Chulani, Software development cost estimation approaches - a survey. Annals of Software Engineering 10 (2000) 177-205.

[16] N.P.B. Bollen, Real options and product life cycles, Management Science 45 (1999) 670-684.

[17] P. Brandimarte, Numerical Methods in Finance and Economics - A MATLAB-Based Introduction, second ed., Hoboken, New Jersey: John Wiley and Sons P, 2006.

[18] K. Braunwarth, B. Heinrich, IT-service-management - a model for determining the impact of interoperability standards on the integration of external IT service providers, Wirtschaftsinformatik 50 (2008) 98-110.

[19] D. Brigo, A. Dalessandro, M. Neugebauer, F. Triki, A stochastic processes toolkit for risk management. Accessed 06.07.2015 at [http://ssrn.com/abstract=1109160].

[20] E. Carmel, P. Tjia, Offshoring Information Technology, third ed. Cambridge University Press, Cambridge, 2005.

[21] V. Cortellessa, F. Marinelli, P. Potena, An optimization framework for "build-or-buy" decisions in software architecture, Computers and Operations Research 35 (2008) 3090-3106.

[22] H. Demirkan, R.J. Kauffman, J.A. Vayghan, H.-G. Fill, D. Karagiannis, P.P. Maglio, Service-oriented technology and management: perspectives on research and practice for the coming decade, Electronic Commerce Research \& Applications 7 (2008) 356-376.

[23] Deutsche Bundesbank (2015). New business (volumes) of German banks/Loans for consumption to households, Accessed 06.07.2015 at [http://www.bundesbank.de/Navigation/EN/Statistics/ Time_series_databases/Macro_economic_time_series/its_details_value_node.html?nsc=true\&tsId=B BK01.SUD230].

[24] J. Dibbern, T. Goles, R. Hirschheim, B. Jayatilaka, Information systems outsourcing: a survey and analysis of the literature. The Data Base for Advances in Information Systems 35 (2004) 6-102.

[25] C. Dorsch, B. Häckl, Combining models of capacity supply to handle volatile demand: the economic impact of surplus capacity in cloud service environments, Decision Support Systems 58 (2014) 3-14.

[26] B.L. Dos Santos, Justifying investments in new information technologies, Journal of Management Information Systems 7 (1991) 71-90.

[27] S.R. Eliason, Maximum Likelihood Estimation: Logic and Practice (Quantitative Applications in the Social Sciences), Sage Publications, Newbury Park, 1993.

[28] C.-O. Ewald, Z. Yang, Utility based pricing and exercising of real options under geometric mean reversion and risk aversion toward idiosyncratic risk, Mathematical Methods of Operations Research 68 (2008) 97-123.

[29] P.H. Farquhar, State of the art - utility assessment methods, Management Science 30 (1984) 12831300.

[30] M. Fischbach, T. Puschmann, R. Alt, Service lifecycle management, Business \& Information Systems Engineering Catchword (2013) 45-49.

[31] V. Gonçalves, P. Ballon, Adding value to the network: mobile operators' experiments with softwareas-a-service and platform-as-a-service models, Telematics and Informatics 28 (2011) 12-21.

[32] S. Gosh, X. Li, Meta-staged projects - valuing the migration to SOA, Information Systems Research 24 (2013) 1011-1027.

[33] R. Heffner, SOA Adoption: Budgets Don’t Matter Much, Cambridge, Forrester Research, 2008.

[34] B. Heinrich, A. Huber, S. Zimmermann, Make-and-sell or buy of web services - a real option approach, Proceedings of the 19th European Conference on Information Systems (2011).

[35] F. Hubalek, W. Schachermayer, The limitations of no-arbitrage arguments for real options, 
International Journal of Theoretical Applied Finance 4 (2001) 361-373.

[36] J.C. Hull, Options, Futures, and Other Derivates, eighth ed. Pearson Education Inc.: Upper Saddle River, 2012.

[37] P.C. Jha, R. Kaur, S. Bali, S. Madan, Optimal build-or-buy decision for component selection of application package software, SEMCCO Part II (2013) 546-558.

[38] M. Jorgensen, M. Shepperd, A systematic review of software development cost estimation studies, IEEE Transactions on Software Engineering 33 (2007) 33-53.

[39] R.J. Kauffman, B. Konsynski, C.H. Kriebel, Evaluating research approaches to IT business value assessment with the senior management audience in mind: a question and answer session. Idea Group Strategic Information Technology Management Series Vol. 1 (1993) 573-593.

[40] C.P. Klaus, F. Krause, C. Ullrich, Determining the business value of volume flexibility for service providers - a real options approach. Proceedings of the 22nd European Conference on Information Systems (2014).

[41] J. Klostermeier, Die SOA-Strategie der Schweizer Bank: Credit Suisse setzt 2.200 web-services ein. CIO Online, Accessed 16.06.2015 at [http://www.cio.de/858941].

[42] P. Kodukula, C. Papudesu, Project Valuation Using Real Options: A Practitioners Guide, J. Ross Publishing Inc., Fort Lauderdale, 2006.

[43] B. Kogut, N. Kulatilaka, Operating flexibility, global manufacturing and the option value of a multinational network, Management Science 40 (1994) 123-139.

[44] R.L. Kumar, A note on project risk and option values of investments in information technologies, Journal of Management Information Systems 13 (1996) 187-193.

[45] R.L. Kumar, Managing risks in IT projects: an options perspective, Information \& Management 40 (2002) 63-74.

[46] M.C. Lacity, S.A. Khan, L.P. Willcocks, A review of the IT outsourcing literature: insights for practice, Journal of Strategic Information Systems 18 (2009) 130-146.

[47] M.C. Lacity, S.A. Khan, A. Yan, L.P. Willcocks, A review of the IT outsourcing empirical literature and future research directions, Journal of Information Technology 25 (2010) 395-433.

[48] F. Lefley, Approaches to risk and uncertainty in the appraisal of new technology capital projects, International Journal of Production Economics 53 (1997) 21-33.

[49] C. Legner, Is there a market for web-services?, ICSOC 2007 Workshops (2009) 29-42.

[50] C.D. Lewis, Demand Forecasting and Inventory Control: A Computer Aided Learning Approach. Woodhead Publishing Ltd, Cambridge, 1997.

[51] V. Mahajan, E. Muller, F.M. Bass, New product diffusion models in marketing: a review and directions for research, The Journal of Marketing 54 (1990) 1-26.

[52] W. Margrabe, The value of an option to exchange one asset for another, Journal of Finance 33 (1978) 177-186.

[53] Mastercard (2016). Accessed 20.03.2016 at [https://developer.mastercard.com/portal/display/ api/Fraud+Scoring+for+Merchants].

[54] R. Matros, P. Stute, N.H. von Zuydtwyck, T. Eymann, Make-or-buy im cloud computing - ein entscheidungsorientiertes modell für den bezug von amazon web services. Bayreuth Reports on Information Systems Management 45 (2009).

[55] J.R. Meredith, A. Raturi, K. Amoako-Gyampah, B. Kaplan, Alternative research paradigms in operations, Journal of Operations Management 8 (1989) 297-326.

[56] R.C. Merton, On the pricing of corporate debt: the risk structure of interest rates, Journal of Finance 29 (1974) 449-470.

[57] G.E. Metcalf, K.A. Hassett, Investment under alternative return assumptions: comparing random walks and mean reversion, Journal of Economic Dynamics and Control 19 (1995) 1471-1488. 
[58] F. Modigliani, M.H. Miller, The cost of capital, corporation finance and the theory of investment, The American Economic Review 48 (1958) 261-297.

[59] MuleSoft (2016). Accessed 20.03.2016 at [https://www.mulesoft.com/lp/whitepaper/api/api-ledconnectivity].

[60] M.P. Müller, S. Stöckl, S. Zimmermann, B. Heinrich, Decision support for IT investment projects a real option analysis approach based on relaxed assumptions, Business \& Information Systems Engineering (2016) online first 1-16.

[61] B. Mueller, G. Viering, C. Legner, G. Riempp, Understanding the economic potential of serviceoriented architecture, Journal of Management Information Systems 26 (2010) 145-180.

[62] M. Nüttgens, I. Dirik, Business models of service-oriented information systems - a strategic approach towards the commercialization of web services, Wirtschaftsinformatik 50 (2008) 31-38.

[63] M.Q. Patton, Qualitative research and evaluation methods. Sage Publications: USA, 2002.

[64] M.T. Pich, C.H. Loch, A.D. Meyer, On Uncertainty, Ambiguity, and Complexity in Project Management, Management Science 48 (2002) 1008-1023.

[65] B. Rossi, How an API-first approach is driving digital transformation in banking. Information Age (2015), Accessed 20.03.2016 at [http://snip.ly/kv4l7\#http://www.information-age.com/technology/ applications-and-development/123460319/how-api-first-approach-driving-digital-transformationbanking].

[66] H.J. Rubin, I.S. Rubin, Qualitative interviewing: the art of hearing data. third ed. SAGE: USA, 2011.

[67] S. Sarkar, The effect of mean reversion on investment under uncertainty, Journal of Economic Dynamics and Control 28 (2003) 377-396.

[68] Schufa, SCHUFA Kredit-Kompass 2010: Empirische Indikatoren der privaten Kreditaufnahme in Deutschland, Accessed 16.06.2015 at [http://www.schufa-kredit-kompass.de/media/teamweb services/downloads/schufakreditkompass_2010.pdf].

[69] Schufa, SCHUFA Kredit-Kompass 2012:Empirische Indikatoren der privaten Kreditaufnahme in Deutschland, Accessed 16.06.2015 at [http://www.schufa-kredit-kompass.de/media/teamweb services/downloads/schufa_kredit-kompass_2012.pdf].

[70] Schufa, SCHUFA Decision Support System (SCHUFA-DSS), Accessed 16.06.2015 at [https://www.schufa.de/en/en/produkteundservices_en/systemsolutions/systemlsungen.jsp].

[71] E.S. Schwartz, C. Zozaya-Gorostiza, Investment under uncertainty in information technology: acquisition and development projects, Management Science 49 (2003) 57-70.

[72] R. Shang, J. Huang, Y. Yang, R.J. Kauffman, Analyzing the impact of cloud services brokers on cloud computing markets, Reasearch Collection School of Information Systems (2013), Accessed 06.07.2015 at [http://ink.library.smu.edu.sg/sis_research/2110].

[73] W.F. Sharpe, Capital asset prices: a theory of market equilibrium under conditions of risk, Journal of Finance 19 (1964) 425-442.

[74] G. Sick, Real Options, Handbooks in Operations Research and Management Science - Fin., NorthHolland, Amsterdam, 1995, 631-689.

[75] C. Singh, R. Shelor, J. Jiang, G. Klein, Rental software valuation in IT investment decisions, Decision Support Systems 38 (2004) 115-130.

[76] N. Su, R. Akkiraju, N. Nayak, R. Goodwin, Shared services transformation: conceptualization and valuation from the perspective of real options, Decision Sciences 40 (2009) 381-402.

[77] Q.C. Tang, H. Cheng, Optimal location and pricing of web services intermediary, Decision Support Systems 40 (2005) 129-141.

[78] B. Tansey, E. Stroulia, Valuating software service development: integrating COCOMO II and real options theory, Proceedings of 29th International Conference on Software Engineering Workshops (2007). 
[79] A. Taudes, Software growth options, Journal of Management Information Systems 15 (1998) 165185.

[80] A. Taudes, M. Feurstein, A. Mild, Options analysis of software platform decisions: a case study, MIS Quarterly 24 (2000) 227-243.

[81] TechTarget and Forrester Research, State of SOA 2010: executive summary. Accessed 16.06.2015 at [http://cdn.ttgtmedia.com/searchSOA/downloads/TTAG-State-of-SOA-2010-execSummary-wo rking-523\%5B1\%5D.pdf].

[82] K. Umapathy, S. Purao, A theoretical investigation of the emerging standards for web services. Information Systems Frontiers 9 (2007) 119-134.

[83] UPS (2016). Accessed 20.03.2016 at [https://www.ups.com/content/us/en/bussol/browse/ addressvalidationstreetlevel.html].

[84] W3C, Web Services Glossary, Accessed 16.06.2015 at [http://www.w3.org/TR/ws-gloss/].

[85] J.-J. Wang, Z.-K. Lin, H. Huang, A decision model for information systems outsourcing: using a multicriteria method, Journal of Service Sciences \& Management 1 (2008) 1-9.

[86] T. Williams, A classified bibliography of recent research relating to project risk management, European Journal of Operational Research 85 (1995) 18-38.

[87] C. Yang, J.-B. Huang, A decision model for IS outsourcing, International Journal of Information Management 20 (2000) 225-239.

[88] Y. Zhao, M. Helander, K. Sandhal, J. Karsson, Decision making for make vs. buy of software components, Proceedings of 2nd Conference on Computer Science and Systems Engineering (1999) 207-215.

[89] J.L. Zhao, M. Tanniru, L.-J. Zhang, Services computing as the foundation of enterprise agility: overview of recent advances and introduction to the special issue, Information Systems Frontier 9 (2007) 1-8.

[90] S. Zimmerman, A. Katzmarzik, D. Kundisch, IT sourcing portfolio management for it services providers: an approach for using modern portfolio theory to allocate software development projects to available sites, ACM SIGMIS Database 43 (2012) 24-45. 